\title{
PHYSICAL CULTURE AND SPORTS ACTIVITIES IN SELF-PRESERVING BEHAVIOR OF STUDENTS
}

\author{
Olga Pavlovna Kokoulina ${ }^{1 *}$, Yuliya Alekxandrovna Davydova ${ }^{2}$, Ekaterina Vladimirovna \\ Kargapolova $^{2}$, and Oleg Nikolaevich Glazynov ${ }^{2}$ \\ ${ }^{1}$ Department of Physical Education, Plekhanov Russian University of Economics, Russian Federation \\ ${ }^{2}$ Department of political science and sociology, Plekhanov Russian University of Economics, Russian \\ Federation
}

\begin{abstract}
The purpose of the research is to identify the role of physical culture and sports activities on the practice of students' self-preservation behavior. The materials: The research was based on an online questionnaire which was held among 2503 students in REU Plekhanov (Moscow) in October 2019 under E. V. Kargapolova leadership. The results: The most common practices of self-preservation behavior are walking outside, physical education classes and regular sports. The most preferable kinds of sports for students were football, basketball and volleyball. The less preferable were Eastern health practices. Nevertheless, only half of students were regularly engaged in physical education activities. Most of respondents consider they are able to make a set of training exercises and a rational diet. Conclusions: There are several contradictions in students' behavior values of self-preservation and their practices of sport activities. The majority of respondents understand the importance of a healthy lifestyle. Nevertheless, students do not always follow these practices in their daily routine. There is a strong correlation between their health and regular sport assessment, especially. This was due to the presence of a physical education system in higher educational institutions. That's why universities are the most important platform for sports activities.
\end{abstract}

\section{Introduction}

Youth health is an important indicator of our country's future potential. Health is a physical resource for maintaining social capital that can generate incomet. Therefore, the study of conditions and factors of the formation of young people's health has presented a great interest in the scientific community. One of these factors is self-preservation behavior. It is a complex system of interrelated elements which directly affect each other. Typically, there are two levels in the structure of self-preserving behavior: vital-behavioral associated with the individual decisions and actions and vital attitude. The last includes expectations,

\footnotetext{
* Corresponding author: kokoulinaop@mail.ru
} 
motives, values and emotional-evaluative componentsł. Expectations act as a vital attitude cognitive component and are expressed in accepted norms of a general healthy lifestyle. Motive is a cognitive element which is characterized by orientations of self-preserving behavior. Emotional-evaluative component is responsible for emotions and experiences based on which person makes actions related to his/her health. The vital attitudes determine the individual health quality and form a healthy lifestyle. The integral part of it is sport. Additionally, health is a part of social capital that allows the younger generation to realize themselves as future specialists§.

In Russian sociology the self-preserving behavior concept was formulated in the 80's of the XX century by I. V. Zhuravleva, L. S. Shilova, A. I. Antonov [1]. But even now it has not lost its relevance and it is still the subject of scientific discourse. M.A.Gruzdeva and A.V. Korolenko noted that self-preserving behavior "can be negatively directed (selfdestructive) or positively directed (a healthy lifestyle)". They also concluded that in comparison with other demographic groups, young people's behavior had a specific character of their health. On the one hand, it has valuable orientations to preserve and to promote health. On the other hand, there are self-destructive practices in their life.** $\mathrm{K}$. A. Ozerova highlighted a physical culture and sport among the most significant components of self-preservation behavior and concluded that "students do not try to systematically follow the self-care principles ". E. Yu. Bashkueva also drew attention to the fact that "the selfpreservation behavior problem lies in contradiction between consciousness and behavior." A number of researchers noted that the self-preservation behavior determinants of individual characteristics are values and beliefs, needs and motives, attitudes and imbalances system, and one's own health responsibility. D. I. Petrosyan, E. V. Zubkova and N. I. Polyakova concluded that for the majority of students "involvement in the physical education and sports is a socially approved behavior". The question of motivation for selfpreservation behavior remains interesting for researchers. N. A. Usachev and N. I. Ponomareva considered that sports and mass events which were held in the higher education institutions has significantly increased the students' motivation to a healthy lifestyle. E.G.Ermakova noted that the leading motives, as the most important factor of selfpreservation behavior, for students to the physical culture and sports activities are the communicative "sports in the group (tourism, health running, cycling)". Among the reasons that affect the interest of students, A. A. Valebnaya, A. A. Makarova and L. V. Kumm mentioned the presence of "a large number of sections and sports teams, as well as the achievements stands". E. A. Mitrokhin identified a motivation type as a need for selfexpression in its research. Thus, the self-preserving behavior concept is closely related to the healthy lifestyle. Physical culture and sports activities occupy an important place in the modern youth self-preservation behavior structure.

\section{Materials and methods}

We used a sociological study "A physical culture and sport in the megapolis student's life", which was implemented under the leadership of E. V. Kargapolova in October 2019. The main method of collecting sociological information was an online survey. In the data array, 2503 questionnaires of students from Moscow universities were selected for processing, of which $41 \%$ were boys, $59 \%$ were girls, aged $16-17$ years- $8.7 \%$, 18-19 years- $64.8 \%, 20-21$ years $-18.2 \%, 22-23$ years $-4.3 \%, 24$ years and older $-4 \% .73 .7 \%$ of respondents study in the $1 \mathrm{st}-2$ nd year, $19.8 \%$ in the 3 rd - 4 th year, and $6.4 \%$ in the 5 th year. The distribution 
according to the study profile is as follows: economic sciences $-22.9 \%$ of the respondents, economic sciences- $22.9 \%$, social and humanitarian sciences- $22.5 \%$, technical sciences$20.5 \%$, management sciences- $12.7 \%$, legal sciences - $6.6 \%$, natural sciences- $5.3 \%$, architecture and art-3.8\%, military sciences- $0.5 \%$ Students were asked the following questions: «How do you assess your health status?», «Do you know the indicators that characterize the your physical condition level?», «What does you prevent from engaging in a physical culture and sports activities?», «What wellness procedures do you use in your life?», «What sports are you currently doing?», «What motivates you to engage in physical culture and sports activities?», «Would you be able to do it yourself at the moment?». The results of the research cannot be considered representative. However, the large number of respondents allows us to draw meaningful conclusions.

\section{Results}

An investigation revealed that students are familiar with the main models of selfpreservation behavior and understand the importance of sports and physical activity as a part of these models. The human health is a phenomenon influenced by many factors. But the leading role in this broad set of causes belongs to the behavioral factor, which is largely determined by the consideration of person's health from his/her point of view. The distribution of answers on the question "How do you evaluate your health?" Is the following: $48.9 \%$ of respondents picked the option "the normal health, not complaining yet", 34.9\% -"I am sometimes ill", 9.6\% - "I have chronic diseases" and 4.3\% - "I am often ill", $0.9 \%$ - disabled (fig. 1). It is obvious that the majority of students evaluate their health status as good, which is objectively explained by the age characteristics of this category. Young people aged 18-22 years have a slight degree of chronic diseases (according to our survey, this is one 10th ).

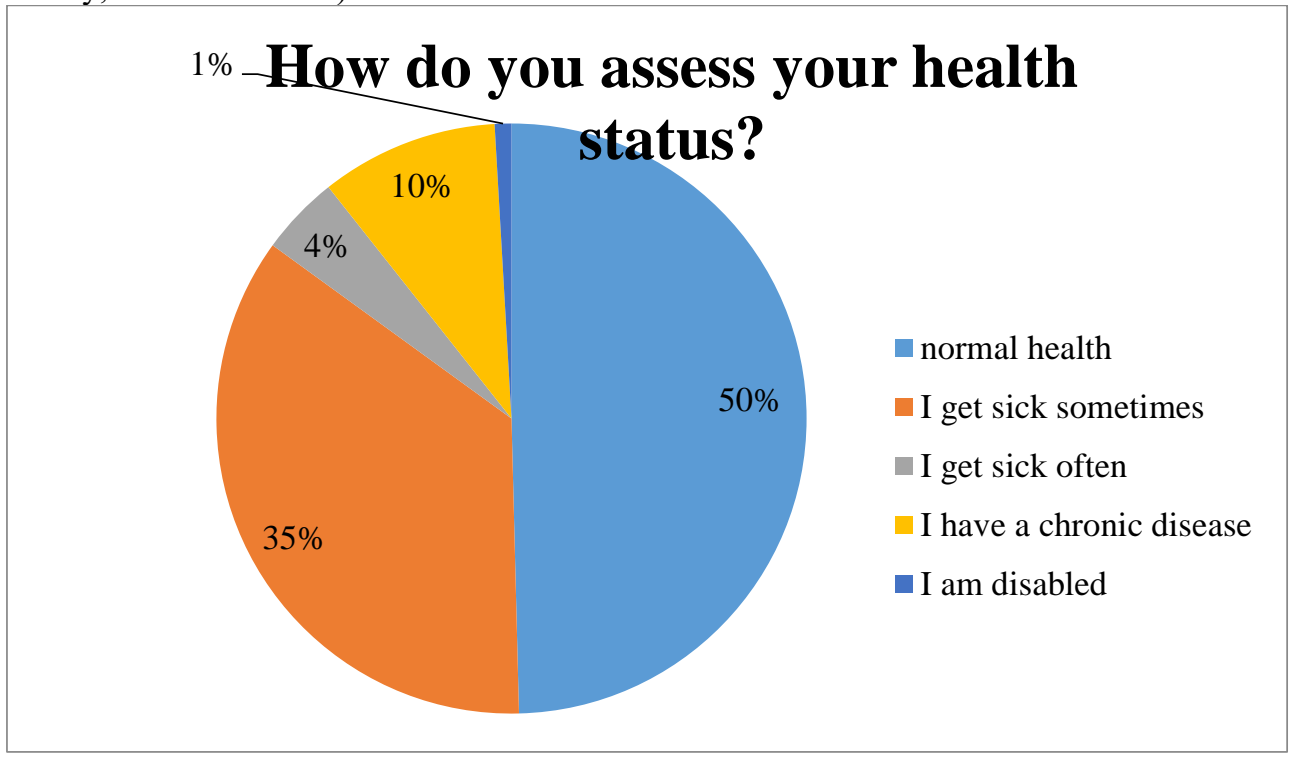

Fig. 1. Students ' answers to the question "How do you assess your health?" (100\% of the respondents).

One of the elements of self-preservation behavior is self-diagnosis and self-treatment with the help of home measuring devices. Thus, a modern person should know the physical 
indicators of their health. According to the survey, students were informed about their physical health indicators: $83.6 \%$ of respondents know their height and $78.3 \%$ know their weight. At the same time, we found it surprising that the situation is much worse with such important health characteristics as hemoglobin and blood pressure. More than half of the students do not know the hemoglobin level and more than a third of total do not know about blood pressure indicators. Only one of six students knows the exact indicators of the hemoglobin level, and only one of four students knows blood pressure (table 1). In our opinion, it is necessary to popularize knowledge about the healthy person physical indicators, their relationship with physical culture and sports activities, and ensure the wide dissemination of such information among young people

As well as the researcher of the problem E. Yu. Bashkueva we can note the contradictions in the students self-preservation attitudes which are characterized by "the gap presence between the high knowledge level of in the health protection, a healthy lifestyle sphere and their insufficient practical implementation" [2, p. 154]. For example, now it is a fashion trend to lead a healthy lifestyle, to practice sport and to visit fitness centers. But respondents noted that they have a lack of time for such activities. This factor was indicated by $72.9 \%$ of students (fig.2). The respondents also indicated their personal characteristics: $36.8 \%$ of the surveyed students chose the answer "not enough willpower".

Table 1. Students ' answers to the question "Do you know the indicators that characterize the your physical condition level ?" (\%of the respondents).

\begin{tabular}{|l|c|c|c|}
\hline \multirow{2}{*}{ Indicator } & \multicolumn{3}{|c|}{ Answer variant } \\
\cline { 2 - 4 } & Know & Know approximately & Do not know \\
\hline Height & 83.6 & 15.1 & 1.2 \\
\hline Weight & 78.3 & 20.3 & 1.4 \\
\hline Blood pressure & 26.2 & 38.2 & 35.7 \\
\hline Haemoglobin & 15.9 & 27.3 & 56.8 \\
\hline
\end{tabular}

Among the main problems of self - preservation behavior was the lack of regular physical education and sports. Only $58.3 \%$ of respondents regularly attend classes at the University (table.2). 52\% of students are engaged in sports on a permanent basis. The most popular wellness procedure was walking in the fresh air. This option was picked by $74.1 \%$ of respondents. 


\section{What does you prevent from engaging in a physical culture and sports activities?}

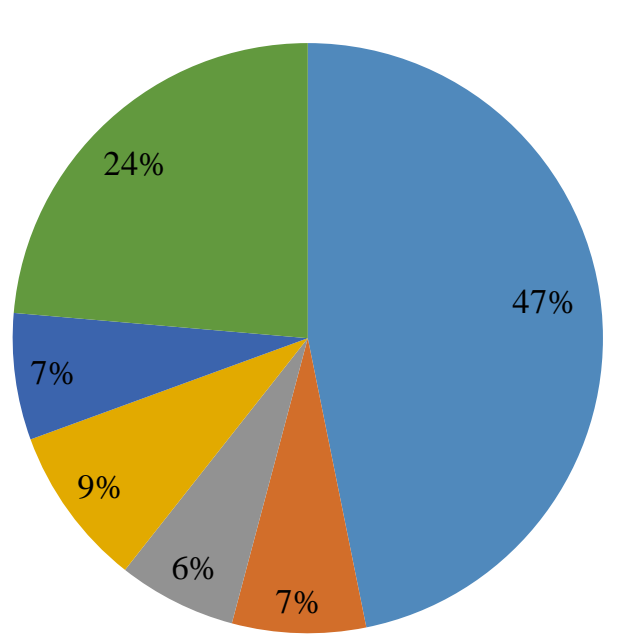

- Lack of free time

- there is not enough physical education knowledge to organize independent classes

$\square$ lack of equipment

there is no sport club in the University

Fig. 2. Students ' answers to the question " What does you prevent from engaging in a physical culture and sports activities?" (\% of respondents).

The stairs walking is quite popular instead of the elevator among the students $(56.4 \%$ use this practice). Only a small number of students do morning exercises. "Always" was performed by $13.3 \%$ of the respondents, "sometimes" -by $15.4 \%$ of the respondents, and "never or as necessary" - by one in three. The result about Eastern health methods improvement in the physical culture and sports activities of young people seemed unexpected for us. Despite their popularity and availability (there is a huge number of videos on this topic on the Internet), our study has shown that they are not widely distributed among students: $43.1 \%$ never do yoga, $36.7 \%$ never do meditation, and $29.1 \%$ never do breathing exercises. Yoga was the least popular among all three practices. It is obvious that these classes, which usually last 1.5 hours and include a significant proportion of static exercises, do not particularly attract young people who usually spend a lot of time without movement, at home, behind the computer or at a desk at University. Therefore, we can assume that they prefer more dynamic exercises. Only one of four students regularly attend a fitness center or gym, what indicates a limited access to healthy lifestyle infrastructure. Unfortunately, gym or fitness center membership is quite expensive, which makes it not affordable for everyone.

Also, every third student runs. The hardening procedures were not particularly popular among students. Only one in five makes them regularly and $36.9 \%$ never. The bath and sauna were more popular. $24.9 \%$ of respondents visit them regularly. These figures are correlated with the fitness centers visits data, on the territory of which there are mostly baths and saunas. "Massage" was chosen by $22.5 \%$ of the respondents. One in five gives a massage as needed or never does. The majority of students have a posture violation or a 
spine curvature resulting in back pain. Additionally, in Moscow almost each fitness center or beauty salon provides the massage services. Therefore, this is a fairly popular wellness procedure.

Another common wellness practice is the exercises for the eyes. The active use of computers, phones and other gadgets since the school time leads to the visual defect among the significant part of young people. The vision correction is also carried out with the help of gymnastics that strengthen the eye muscles. According to our research, students are familiar with this type of vision correction technique: every fourth respondent regularly uses it, and every fifth as necessary.

Table 2. Students' answer to the question "What wellness procedures do you use in your life?»( \% of the respondents).

\begin{tabular}{|l|c|c|c|c|c|c|}
\hline \multicolumn{1}{|c|}{ Procedure } & \multicolumn{5}{|c|}{ Answers variants } \\
\cline { 2 - 7 } & Always & Often & Seldom & $\begin{array}{c}\text { By } \\
\text { necessity }\end{array}$ & Never & $\begin{array}{c}\text { Do not consider } \\
\text { it a means of } \\
\text { preserving } \\
\text { health }\end{array}$ \\
\hline $\begin{array}{l}\text { Exercise in the } \\
\text { morning and } \\
\text { evening }\end{array}$ & 13.3 & 15.4 & 30.3 & 20.0 & 20.1 & 1.0 \\
\hline $\begin{array}{l}\text { Stretching } \\
\text { exercises }\end{array}$ & 12.8 & 21.5 & 31.7 & 19.2 & 13.7 & 1.1 \\
\hline $\begin{array}{l}\text { Walking on the } \\
\text { stairs instead of } \\
\text { the elevator }\end{array}$ & 25.4 & 31.0 & 24.0 & 11.5 & 7.0 & 1.2 \\
\hline Fitness, gym & 17.7 & 21.1 & 29.4 & 15.4 & 15.4 & 0.9 \\
\hline Athletics & 24.2 & 27.8 & 27.4 & 14.0 & 5.8 & 0.9 \\
\hline $\begin{array}{l}\text { Attending physical } \\
\text { education classes } \\
\text { at the University }\end{array}$ & 33.4 & 24.9 & 17.7 & 9.3 & 11.8 & 2.9 \\
\hline Yoga & 8.9 & 9.9 & 18.2 & 15.1 & 43.1 & 4.8 \\
\hline $\begin{array}{l}\text { Hardening } \\
\text { procedures }\end{array}$ & 8.8 & 11.1 & 20.9 & 18.2 & 36.9 & 4.1 \\
\hline Walking in the air & 37.5 & 36.6 & 16.8 & 6.6 & 2.0 & 0.5 \\
\hline $\begin{array}{l}\text { Breathing } \\
\text { gymnastics }\end{array}$ & 11.8 & 14.2 & 24.6 & 1,2 & 29.1 & 4.0 \\
\hline Meditation & 9.8 & 11.1 & 19.7 & 15.6 & 36.7 & 7.1 \\
\hline Massage & 9.4 & 13.1 & 26.5 & 23.1 & 24.5 & 3.4 \\
\hline Bath, sauna & 9.4 & 15.5 & 30.3 & 20.4 & 20.2 & 4.3 \\
\hline Runs & 12.0 & 17.9 & 28.7 & 18.2 & 20.4 & 2.8 \\
\hline $\begin{array}{l}\text { Gymnastics for the } \\
\text { eyes }\end{array}$ & 10.2 & 14.2 & 23.3 & 23.4 & 24.7 & 4.2 \\
\hline
\end{tabular}

The effective human body is possible only in conditions of motor activity which restrains the negative age-related changes and promotes longevity. The youth's choice between any form of movement is one of the self-preservation behavior practices. And here we can observe the leading role of sport. It seemed interesting to us to find out what kind of sports young people prefer today. First of all, we would like to note that only $3 \%$ of the respondents do not play sports at all. The sport games, such as volleyball, football and basketball, have reached the greatest popularity among students. In total, $39.9 \%$ of respondents are engaged in them. What corresponds to their gender cross-section $(36.4 \%$ of men and $63.6 \%$ of women). Mostly, they are young men. The second place was taken by such sports as swimming (27.1\%) (figure 3). The swimming has a healing and hardening 
effect, which makes it so popular. Additionally, in Moscow and in Moscow regions the sport infrastructure and recreation complexes are developed: there are swimming pools, fitness clubs with pools, public pools at schools and at universities which allow students to choose both: pay at an affordable price or free classes option. Dance was not less popular. This direction has been actively positioned in recent years on television and on the Internet. What is more, they can be practiced not only at Universities, dance halls and fitness centers but also at home using videos at any convenient time. $7 \%$ and $6.7 \%$ of students are engaged in running and athletics, respectively. About the same percentage of students choose gymnastics and tennis. These sports are preferred by 6.2 and $5.7 \%$ of students. It seemed paradoxical to us that a small percentage of respondents are engaged in power single combats. Among young men surveyed more than one-third. Only 5.1\% of students are engaged in boxing and $4.4 \%$ in karate. According to the statistically significant values, yoga took the last place. This kind of sport is more popular among mature, older age people, and young people, as we have already noted dynamic and active sports are more popular among.

\section{The 5 most popular sports according to the respondents}

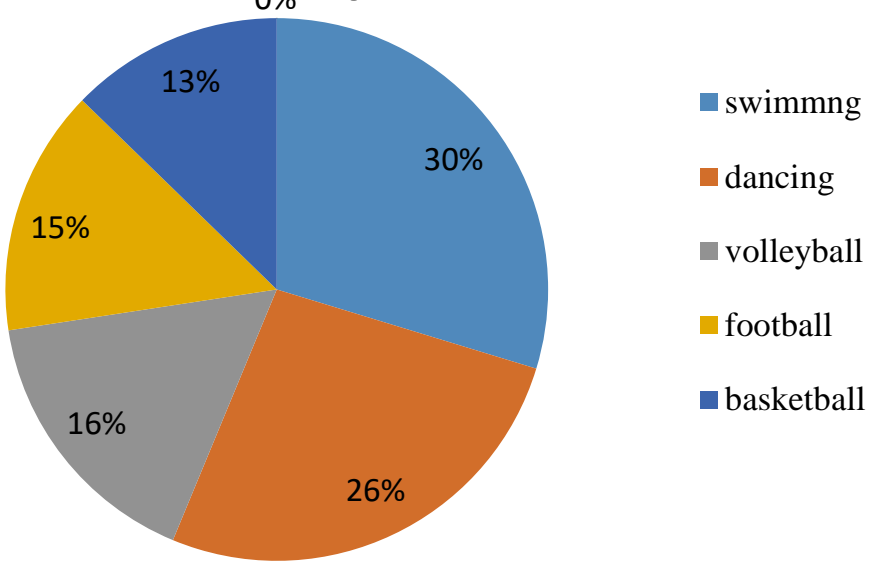

Fig. 3. Sports that students do (\% of respondents).

It also seemed logical to find out what motivates respondents to play sports. The research results revealed that $66.7 \%$ of the students do this in order to optimize the weight and improve their body shape (Table 3 ). 
Table 3. The students ' answers to the question "What motivates you to engage in physical culture and sports activities?».

\begin{tabular}{|l|c|}
\hline \multicolumn{1}{|c|}{ Answer variant } & \% of the respondents \\
\hline The desire to improve physical fitness & 58.9 \\
\hline The desire to optimize the weight and improve the shape & 66.7 \\
\hline The desire to maintain the health & 51.7 \\
\hline $\begin{array}{l}\text { The sports discipline helps to increase the efficiency in the daily tasks } \\
\text { solving }\end{array}$ & 31.4 \\
\hline Relieve fatigue & 33.3 \\
\hline Improve performance & 30.4 \\
\hline Cultivate a beautiful manner and culture of movement & 20.9 \\
\hline Achieve sporting success & 14.0 \\
\hline Cultivate a will, character, and purpose & 33.4 \\
\hline Spend the time efficiently & 25.3 \\
\hline Get a physical education credit on time & 29.5 \\
\hline
\end{tabular}

The two-thirds of respondents picked the answer "a desire to improve physical fitness" and only one third picked "a desire to maintain health" option. These results showed that primarily the young people paid attention to the aesthetic component of physical culture and sport activities and only then thought about it as one of the practices of selfpreservation behavior.

Self-control and the training regularity are the significant components of sports and physical activity. Therefore, one of the research aspects was aimed to find out how much students are independent in this process (Table 4). $78 \%$ of the respondents could make a morning exercises complex as the most important component of a healthy lifestyle but only $28.7 \%$ do it regularly (Table2). In our opinion, students overestimate their abilities in this matter, since a competent complex of morning exercises is designed to work out different muscle groups taking into account the person's physical characteristics and is designed for a certain time. Consequently, you can only create a successful complex under the specialist guidance. $83.2 \%$ of the respondents can conduct self-monitoring of their physical condition during the physical education and sport activity. That is also doubtful since the survey results showed that students do not know their hemoglobin level and to a large extent their blood pressure (Table 1). $74.4 \%$ of the respondents believe that they will be able to conduct a full-fledged training session. What also does not fully correspond to reality, in our opinion.

Table 4. The students' answers to the question:" Would you be able to do it yourself at the moment..." (\% of the respondents).

\begin{tabular}{|l|c|c|c|}
\hline Answer variant & Yes & I think so & No \\
\hline Make a morning hygienic gymnastics complex & 39.1 & 38.9 & 21.9 \\
\hline $\begin{array}{l}\text { Conduct a physical condition self-monitoring } \\
\text { during a physical education and sports }\end{array}$ & 39.0 & $44 . .2$ & 16.8 \\
\hline Conduct a training session & 37.4 & 37.0 & 25.6 \\
\hline Make a rational diet & 28.8 & 37.8 & 33.4 \\
\hline Give an advice on the hardening & 17.3 & 20.8 & 61.8 \\
\hline Do a self-massage & 26.8 & 35.0 & 38.3 \\
\hline Do a massage to another person & 40.5 & 37.4 & 22.1 \\
\hline
\end{tabular}

According to our research results, only $52 \%$ of the students regularly do exercises and only a third of the respondents regularly visit gym and fitness centers (Table2), but more than two-thirds of them believe that they can take on the role of a professional coach. $66.6 \%$ of the students can make a rational diet. Indeed, you can find a sufficient number of 
a wide dietary dishes variety with calories, menus for each day etc. on the Internet. But you should not forget that every person is individual; before you make a diet menu you need to pass surveys and tests and to consult a doctor. A third of students are ready to give tempering advice which corresponds to the figures shown in Table 2: about the same number of them are engaged in tempering procedures and accordingly can give advice. $61.8 \%$ of them are able to do self-massage. What is generally true, since such practices are widely described in the literature, are easily accessible on the Internet and are used in many physical education classes both in Universities and in fitness centers.

Much more concerns are caused by the willingness to massage another person. $77.4 \%$ of the students believe that they can do it. It is doubtful that the students are fully aware that the massage is a medical procedure that has many contraindications and is prescribed by a doctor. Thus the results of our research showed that respondents exaggerate their ability to independently master the self-preservation behavior practices.

\section{Conclusions}

Based on the research we can identify three models of young people's self-preservation behavior:

- the traditionalists - those who set the goal keep fit and use generally accepted traditional methods for this purpose;

- the innovators - people who understand the importance of health and are looking for the new ways to preserve it;

- the dophenists - those who are indifferent to their health, they take it for granted and don't care about maintaining it.

According to the results of our research, we can assume that the majority of students can be attributed to traditionalists, one in ten of them is an innovator and about $1 / 5$ th of them are the dophenists who believe that they do not need to maintain their health.

Most of the respondents consider health as the result of their own efforts and believe that a healthy lifestyle is necessary, in order to maintain themselves in a good body shape. Students have an idea of how self-preservation behavior practices should be used in order to maintain health and performance. A direct relationship was found between their health assessment and regular sports and physical education which are influenced by the presence of the physical education system at universities. The regularity of sport activities does not depend on the respondent's gender whereas distribution is strongly correlated by gender. Generally, the students' degree involvement in the various forms of motor activity is quite high.

More than a half of students note that their physical activity is manifested primarily in physical and sports education at university, which will allow us to conclude that the system of physical training in higher education institutions forms a stable practice of regular motor activity and contributes to the development of self-preservation behavior. The educational environment in university is one of the most accessible platforms for promoting a healthy lifestyle. It also contributes to the realization of the creative, professional and physical potential of modern students.

\section{References}

1. Antonov A. I. Family microsociology/ Structures and processes research methodology. Moscow: Nota Bene, 1998. 360 p. 
2. Bashkueva E. Yu. Ulan-Ude students and working youth health and self-preserving behaviour: socio-economic analysis // Bulletin of the Buryat scientific centre of the Siberian branch of the Russian Academy of Sciences. 2018. no. 2 (30). 151-157 pp.

3. Becker G. Investment in Human Capital: a Theoretical Analysis // The Journal of Political Economy. 1962. Vol. 70. Iss. 5. Part. 2. Investment in Human Beings. P. 9-49.

4. Becker G. Human Capital: A Theoretical and Empirical Analysis, with Special Reference to Education. Chicago, University of Chicago Press, 1993. 402 p.

5. Bloom D. E., Canning D., Graham B. Longevity and Life-cycle Savings // Scandinavian Journal of Economics. 2003. Vol. 105 (September). P. 319-338.

6. Coleman J. Social Capital in the Creation of Human Capital // American Journal of Sociology. 1998. Vol. 94. Supplement. P. 95-120.

7. Coleman J. Foundations of Social Theory. Cambridge: Harvard Univ. Press, 1990. 993 p.

8. Gruzdeva M. A., Korolenko V. A. The young people maintaining health behaviour factors // Health risk analysis. 2018. no. 2. 41-51pp.

9. Ermakova E. G. The physical culture and sports motivation formation among the students //International journal of Humanities and Natural Sciences. 2019. no. 12-1 (39). 100-102 pp.

10. Koshkin A. P., Novikov A.V. Social capital of students and faculty as a resource for improving the quality of education // Espacios. 2018. Vol. 39. No. 23. 23 p.

11. Mitrokhin E. A. The Siberian Institute of Management of the RANEPA branch students' motivation to the physical culture and sports as the individual physical development component / / Physical education of Siberia. 2019. No. 1 (41). 16-18pp.

12. Mikheeva D. A. The students' motivation to the sport and physical culture classes // Science and education: preserving the past, creating the future. Collection of articles of the XXV International scientific and practical conference: in 2 parts. Penza, 2019. 43$45 \mathrm{pp}$.

13. Ozerova K. A. The students' self-preservation behaviour practice evaluation in the context of the University institutional environment // Physical culture and sport in the professional education structure: retrospect, reality and future. The interdepartmental round table materials collection. Ed. by S. M. Struganov. 2017. 375-378 pp.

14. Petrosyan D. I., Zobkova E. V., Polyakova N. N. The physical culture and sport in the students' life (based on the students pilot survey results of the Vladimir branch of the RANEPA) //Scientific notes. 2018. no. 4 (28). 40-46 pp.

15. Simaeva I. N., Alimpieva A.V. The health protection and education: an institutional approach. Kaliningrad: Kant Baltic Federal University named after I.Kant, 2019, 299 p.

16. Usachev N. A., Ponomareva N. I. The sports and mass events complex"Towards the Universiade-2019" as the students' motivation increasing factor to the physical culture and sports // Scientific notes of the University named after P.F. Lesgaft. 2019. No. 5 (171). 357-359 pp.

17. Valebnaya A. A., Makarova A. A., Kumm L. V. Students motivation to the physical culture and sports // Scientific electronic journal Meridian. 2019. no. 13 (31). 246-248 pp.

18. Zhang X. J., Yu P., Yan J., Spil I.-T. A. M. Using diffusion of innovation theory to understand the factors impacting patient acceptance and use of consumer e-health innovations: a case study in a primary care clinic // BMC Health services research. 2015. V. 5. DOI: 10.1186/s12913-015-0726-2. 